\title{
AVALIAÇÃO DA IMUNIDADE CELULAR NOS PACIENTES CO-INFECTADOS PELO VÍRUS DA HEPATITE C E VÍRUS DA IMUNODEFICIÊNCIA HUMANA
}

\author{
Cristiane Valle TOV01, Diogo Edele dos SANTOS², Angelo Zambam de MATTOS², \\ Angelo Alves de MATTOS ${ }^{2}$, Breno Riegel SANTOS ${ }^{1}$ e Bruno GALPERIM ${ }^{1}$
}

\begin{abstract}
RESUMO - Racional - O estado de ativação imune provocado pelo vírus da hepatite C pode agir deleteriamente em indivíduos portadores do vírus da imunodeficiência humana, favorecendo a destruição mais rápida dos linfócitos CD4. Por outro lado, a recuperação imune observada após o início da terapia antiretroviral pode ser parcialmente embotada em indivíduos co-infectados pelo vírus da hepatite C. Objetivo - Avaliar o impacto da co-infecção pelo vírus da hepatite $\mathrm{C}$ na imunidade celular dos pacientes infectados pelo vírus da imunodeficiência humana. Métodos - Foram avaliados pacientes co-infectados por ambos os vírus, atendidos prospectivamente no Ambulatório de Gastroenterologia do Hospital Nossa Senhora da Conceição, Porto Alegre, RS (grupo 1 - 385 pacientes), e monoinfectados pelo vírus da imunodeficiência humana cujos dados foram obtidos através da revisão dos prontuários do Serviço de Infectologia do mesmo Hospital (grupo 2 - 198 pacientes). Foram avaliados dados demográficos (gênero, raça, idade), contagem de células CD4 e CD8, relação CD4/CD8 e carga viral do vírus da imunodeficiência humana. O nível de significância adotado foi de 5\%. Resultados - Não houve diferença estatisticamente significativa quando avaliados os valores médios da contagem de células CD4 (374,7 $\pm 215,7$ x 357,5 $\pm 266,0), \operatorname{CD} 8(1.512,4 \pm 7.274,6$ x 986,7 $\pm 436,4)$ e da carga viral do vírus da imunodeficiência humana $(83.744,2 \pm 190.292,0$ x 104.464,0 $\pm 486.880,5)$, respectivamente nos grupos 1 e 2, bem como na proporção de pacientes com relação CD4/CD8 menor que 1. Conclusão - A co-infecção por estes vírus não trouxe impacto negativo relevante em relação aos monoinfectados pelo vírus da imunodeficiência humana e as características de imunidade foram semelhantes.
\end{abstract}

DESCRITORES - Imunidade celular. Hepacivírus. HIV.

\section{INTRODUÇÃO}

Aproximadamente $2 \%$ a 3\% da população de países desenvolvidos são infectados com o vírus da hepatite $\mathrm{C}$ (VHC). Essa representa atualmente a causa mais freqüente de hepatite crônica e é também a principal indicação para transplante hepático ${ }^{(2,33)}$. A co-infecção por VHC e vírus da imunodeficiência humana (HIV) é comum, principalmente porque ambos os vírus compartilham as mesmas rotas de transmissão, embora a via sexual seja mais importante para o HIV do que para o $\operatorname{VHC}^{(2,6,26)}$.

O estado de ativação imune permanente proporcionado pela infecção pelo VHC pode agir deleteriamente em indivíduos HIV-positivos, favorecendo a destruição mais rápida dos linfócitos $\mathrm{CD} 4{ }^{(28)}$. Por outro lado, a recuperação imune observada após o início da terapia antiretroviral (ARV) efetiva pode ser parcialmente embotada em indivíduos com infecção pelo VHC, através da infecção de células imunes pelo próprio $\mathrm{VHC}^{(28)}$.
Pela importância que essas infecções adquiriram no mundo contemporâneo e pelas eventuais divergências na literatura no que tange à evolução dos pacientes co-infectados, torna-se fundamental que se entenda o comportamento dessas infecções em nosso meio.

O presente estudo teve por objetivo comparar as características de imunidade celular dos pacientes co-infectados por VHC/HIV e dos monoinfectados por HIV.

\section{MÉTODOS}

Foram avaliados dois grupos de pacientes: o grupo 1 foi constituído de pacientes co-infectados por VHC/HIV avaliados prospectivamente e de forma seqüencial no Ambulatório de Gastroenterologia do Hospital Nossa Senhora da Conceição (HNSC), Porto Alegre, RS, no período compreendido entre janeiro de 2000 e maio de 2004; o grupo 2 foi constituído por pacientes monoinfectados por

Hospital Nossa Senhora da Conceição, Porto Alegre, RS.; ${ }^{2}$ Faculdade Federal Ciências Médicas de Porto Alegre, RS.

Correspondência: Dra. Cristiane Valle Tovo - Rua Cel Aurélio Bitencourt, 115 - apt. 201 - 90430-080 - Porto Alegre, RS. E-mail: cris.tovo@terra.com.br 
HIV, sendo os dados obtidos a partir da revisão de prontuários de pacientes portadores de HIV do Serviço de Infectologia do HNSC.

Co-infecção por VHC/HIV (grupo 1) foi definida como pacientes com teste anti-HIV e anti-VHC positivos com HBsAg negativo.

Monoinfecção por HIV (grupo 2) foi definida como pacientes com teste anti-HIV positivo e anti-VHC e HBsAg negativos.

Dados demográficos (gênero, raça, idade), bem como o uso de ARV, foram registrados.

A contagem de células CD4 e CD8 foi realizada por citometria de fluxo conforme orientação do fabricante (Becton Dickinson, Heidelberg, Alemanha).

Os anticorpos anti-VHC foram detectados através do teste ELISA III, de acordo com as instruções de fabricação (Abbott Axsym System, N. Chicago, IL, EUA) e a detecção do RNA-VHC pela técnica da PCR, utilizando o teste qualitativo AMPLICOR (Roche Diagnostics, Nutley, NJ, EUA; limite de detecção: $50 \mathrm{UI} / \mathrm{mL})$.

Anticorpos para o HIV-1/HIV-2 foram detectados pelo teste ELISA II e Immune Chromatrographic Assay Determine (Abbott Axsym System, N. Chicago, IL, EUA). Amostras positivas eram submetidas para confirmação pelo teste de imunofluorescência (Fundação Oswaldo Cruz, Rio de Janeiro, RJ). Resultados indeterminados eram confirmados pelo teste de "western-blot"(15).

A carga viral do HIV foi realizada através da técnica de b-DNA (Bayer Corporation, Tarrytown, NY, EUA; limite de detecção: 50 cópias $/ \mathrm{mL}$ ).

A genotipagem foi realizada através de técnica de polimorfismo do fragmento de restrição, obtido através da secção com enzimas de restrição (RFLP-PCR) ${ }^{(13)}$.

Esta pesquisa foi aprovada pelo Comitê de Ética do HNSC e apresentava risco mínimo para os pacientes. Todos os pacientes avaliados de forma prospectiva assinaram o termo de consentimento informado para participação no estudo.

O programa MsExcel 2000 foi utilizado para armazenamento dos dados; o pacote estatístico SPSS 8.0 (Statistical Package for Social Science) foi utilizado para análise posterior dos resultados.

As variáveis quantitativas foram apresentadas em forma de média e desvio-padrão. Para análises de médias, utilizou-se análise de variância (ANOVA), com comparações múltiplas feitas pelo método de Tukey.

As variáveis qualitativas foram apresentadas em forma de freqüência e percentual. Para verificar as associações entre essas variáveis, utilizou-se o teste qui-quadrado de Pearson, com o recurso complementar da análise de resíduos ajustados para identificar a localização das associações.

O nível de significância assumido foi de 5\%.

\section{RESULTADOS}

Foram avaliados 385 pacientes co-infectados por VHC/HIV (grupo 1) e 198 monoinfectados por HIV (grupo 2).

Os dados demográficos podem ser observados na Tabela 1.

Os pacientes do grupo monoinfectado por HIV eram mais jovens; o sexo masculino foi mais prevalente no grupo dos co-infectados; a maioria dos pacientes era de raça branca nos dois grupos.
Os dados referentes à contagem de células CD4, CD8 e carga viral do HIV podem ser observados na Tabela 2.

A carga viral do HIV foi realizada em 158 (41,0\%) pacientes do grupo 1 e em $125(63,1 \%)$ do grupo 2, sendo indetectável em $70(44,3 \%)$ casos no grupo 1 e em 37 (29,6\%) no grupo 2 $(P=0,011)$.

Não houve diferença estatisticamente significante quando avaliados os valores médios da contagem de células CD4, CD8 e da carga viral do HIV nos grupos 1 e 2, bem como no número de pacientes com relação CD4/CD8 menor que 1 .

Dentre os co-infectados que realizaram genotipagem e contagem de células CD4 $(n=125)$, observou-se que o genótipo 1 esteve associado com contagem de células abaixo de $200 / \mathrm{mm}^{3}$ (13/15 casos $-86,7 \%$ ), enquanto que o genótipo 3 apresentou associação com aqueles

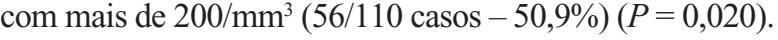

No que tange à terapia ARV, deve ser ressaltado que $39,9 \%$ dos monoinfectados e $61,1 \%$ dos co-infectados não a utilizavam (Tabela 3).

TABELA 1. Dados demográficos

\begin{tabular}{lccc}
\hline & Co-infectados & HIV & $\boldsymbol{P}$ \\
\hline Idade (m \pm DP) & $37,9 \pm 10,0$ & $33,8 \pm 11,2$ & $<0,001 *$ \\
Gênero masc (n, \%) & $292(75,8)$ & $103(52,0)$ & $<0,001 \dagger$ \\
Raça branca (n, \%) & $332(88,5)$ & $154(78,2)$ & $<0,001 \ddagger$ \\
\hline
\end{tabular}

$m=$ média; $D P=$ desvio padrão; $n=$ número de casos; \% = percentagem

* Todas as médias diferem significativamente entre si

Associação significativa entre gênero masculino e o grupo de co-infectados Associação significativa entre raça branca e o grupo de co-infectados

TABELA 2. Avaliação da imunidade

\begin{tabular}{lccc}
\hline & Co-infectados $\mathrm{m} \pm \mathrm{DP}$ & HIV $\mathrm{m} \pm \mathrm{DP}$ & $\boldsymbol{P}$ \\
\hline CD4 (células $\left./ \mathrm{mm}^{3}\right)$ & $374,7 \pm 215,7$ & $357,5 \pm 266,8$ & 0,737 \\
$\mathrm{CD} 8\left(\right.$ células $\left./ \mathrm{mm}^{3}\right)$ & $1.512,5 \pm 7.274,6$ & $986,7 \pm 436,5$ & 0,642 \\
CD4/CD8 <1 (n, \%) & $178(97,3 \%)$ & $142(94,0 \%)$ & 0,333 \\
$\begin{array}{l}\text { Carga viral do HIV } \\
\text { (cópias } / \mathrm{mL})\end{array}$ & $83.744,2 \pm 190.292,0$ & $104.464,0 \pm 486.880,5$ & 0,875 \\
\hline
\end{tabular}

$\mathrm{m}=$ média; $\mathrm{DP}=$ desvio padrão; $\mathrm{n}=$ número de casos; $\%$ = percentagem

TABELA 3. Esquemas de ARV utilizados

\begin{tabular}{lcc}
\hline & Co-infectados $\mathbf{n}(\%)$ & HIV $\mathbf{n}(\%)$ \\
\hline HAART com IP & $42(10,9)$ & $32(16,2)$ \\
HAART sem IP & $76(19,7)$ & $67(33,8)$ \\
Não HAART & $32(8,3)$ & $20(10,1)$ \\
Sem ARV & $235(61,1)$ & $79(39,9)$ \\
Total & $385(100,0)$ & $198(100,0)$ \\
\hline
\end{tabular}

HIV = vírus da imunodeficiência humana; HAART = terapia anti-retroviral altamente ativa; IP = inibidor de protease; ARV $=$ anti-retroviral

\section{DISCUSSÃO}

A co-infecção por VHC/HIV pode ser deletéria em ambos os sentidos: o HIV é importante co-fator para a progressão da hepatopatia causada pelo VHC, aumenta a viremia e pode acelerar a evolução para cirrose ${ }^{(8)}$. Por outro lado, o VHC parece acelerar a progressão da infecção pelo HIV, favorecendo o aumento da CV-HIV e a redução do CD4 ${ }^{(8,24,30)}$. 
O declínio na imunidade celular associado à progressão da infecção pelo HIV, pode aumentar a replicação do VHC e, conseqüentemente, a lesão aos hepatócitos, embora exista pouca correlação entre CV-VHC e grau de lesão hepática. Os linfócitos T têm papel essencial na resolução da infecção aguda pelo $\mathrm{VHC}^{(11)}$. A infecção promovida pelo VHC é controlada pelos linfócitos citotóxicos (CTL), que eliminam os hepatócitos infectados, e pelas citocinas produzidas pelas células $\mathrm{T}$, que inibem diretamente a replicação viral ${ }^{(27)}$. A resposta imune contra a infecção viral ocorre de duas formas: células CD4-T "helper" tipo 1 (Th1) produzem citocinas que ativam a resposta dos CTL, e células CD4-T "helper” tipo 2 (Th2) que induzem a produção de anticorpos contra o VHC. Tem sido sugerido que a pobre resposta às células $\mathrm{CD} 4-\mathrm{Th} 1$ pode estar relacionada à cronicidade da infecção pelo VHC e à progressão da doença hepática relacionada ao $\mathrm{VHC}^{(23)}$. Essa resposta defeituosa pode induzir a alterações nos CTL que, por sua vez, dificultam a eliminação do VHC mais difícil. Essa possibilidade explica a alta CV-VHC em co-infectados pelo HIV, cujas células CD4 têm função e número diminuídos ${ }^{(27)}$. Entretanto, o papel da resposta celular imune na progressão da doença hepática na infecção crônica pelo VHC é menos conhecido.

Um estudo ${ }^{(11)}$ avaliou as diferenças nos padrões de secreção das citocinas na resposta ao VHC em indivíduos com co-infecção por VHC/HIV e em monoinfectados por VHC, e observou que pode haver diminuição da secreção de interleucina-10 (IL-10) pelas células CD4 intra-hepáticas em resposta às proteínas não-estruturais do VHC em co-infectados por VHC/HIV, sugerindo possível implicação da IL-10 na progressão da doença relacionada ao VHC.

$\mathrm{O}$ efeito da infecção pelo VHC na história natural da doença pelo HIV permanece controverso. Estudo de coorte suíço demonstrou que o VHC acelera a progressão da doença pelo $\mathrm{HIV}^{(12,19)}$. Esse estudo prospectivo envolvendo pacientes que iniciaram terapia ARV, observou que o VHC foi independentemente associado com aumento no risco de progressão para síndrome da imunodeficiência adquirida (AIDS) e morte. Demonstrou também que o VHC pode prejudicar a reconstituição imune após a terapia ARV. Indivíduos portadores do VHC foram menos capazes de obter aumento na contagem de células CD4, de pelo menos 50 células $/ \mathrm{mm}^{3}$ em 1 ano após o início dos ARV, quando comparados com indivíduos sem VHC.

PIROTH et al.(21) utilizaram uma coorte longitudinal para demonstrar que a presença de infecção pelo VHC acelerou a progressão clínica e imunológica em estágios precoces da infecção pelo HIV entre usuários de drogas injetáveis e homens que praticam sexo com homens (HSH). LESSENS et al. ${ }^{(18)}$ relataram rápida progressão para AIDS em pacientes co-infectados após o desenvolvimento de doença hepática progressiva em hemofílicos. SABIN et al. ${ }^{(24)}$ mostraram que pacientes co-infectados com VHC genótipo 1 evoluíram mais rapidamente para AIDS ou morte que aqueles co-infectados com outros genótipos do $\mathrm{VHC}$, independentemente de idade na soroconversão e contagem de células CD4 durante o período de seguimento. O estudo de coorte realizado na Johns Hopkins University observou que pacientes co-infectados com contagem basal de células CD4 entre 50 e $200 / \mathrm{mm}^{3}$, progrediam para morte mais rapidamente que aqueles com monoinfecção pelo HIV, embora a morte não estivesse associada ao $\mathrm{VHC}^{(31)}$.

No entanto, alguns autores ${ }^{(9,34)}$ observaram que a presença ou ausência do VHC em pacientes com HIV não influenciou a progressão clínica e imunológica da doença pelo HIV ou a sobrevida $^{(29)}$, bem como a resposta à terapia HAART ${ }^{(22)}$.

Apesar da imunidade no paciente portador de HIV ser avaliada primordialmente através da contagem de células CD4, optou-se no presente estudo por representá-la conjuntamente com os valores médios da carga viral do HIV, já que ambas são intimamente relacionadas e que alterações na carga viral do HIV geralmente implicam alterações na contagem de células CD4.

A característica da AIDS é a depleção seletiva dos linfócitos T CD4. Esse defeito resulta de um tropismo do HIV por esta população de células, devido à alta afinidade da proteína do envelope viral pela célula CD4 ${ }^{(25)}$.

Alguns estudos ${ }^{(3,12)}$ observaram que pacientes co-infectados por VHC/HIV apresentam níveis mais baixos de células CD4 do que os monoinfectados por HIV. No entanto, neste estudo, os valores médios de células CD4 não diferiram nos grupos estudados.

No grupo de pacientes co-infectados VHC/HIV envolvidos no protocolo APRICOT ${ }^{(32)}$ para tratamento, o valor médio das células CD4 era 531 células $/ \mathrm{mm}^{3}$. Em outros estudos que avaliaram o tratamento de pacientes co-infectados, os valores médios foram semelhantes, variando de $478^{(20)}$ a $500^{(5,7)}$ células $/ \mathrm{mm}^{3}$, sendo maiores que o observado na presente série. No entanto, em outros trabalhos que não incluíram apenas pacientes candidatos ao tratamento anti-VHC, a contagem média de células CD4 foi inferior à observada nesta casuística ${ }^{(12,31)}$.

$\mathrm{O}$ estudo de GREUB et al. ${ }^{(12)}$ demonstrou que os pacientes com genótipo 3 eram maioria entre aqueles co-infectados com baixa contagem de células CD4. Este achado pode ser de interesse, pois o conhecimento quanto à patogenicidade dos diferentes genótipos de VHC ainda é limitado. Nesta casuística, o genótipo 1 foi mais prevalente em pacientes co-infectados com contagem de células CD4 abaixo de 200/ $\mathrm{mm}^{3}(86,7 \%)$, e o genótipo 3 , naqueles com mais de $200 / \mathrm{mm}^{3}$ (50,9\%). No entanto, não se pode inferir pior prognóstico em pacientes com genótipo 1 apenas com base neste fato.

A contagem de células CD8 também é utilizada na avaliação da infecção pelo HIV, e já foi demonstrado que a resposta celular CD8 se correlaciona com a resposta celular CD4 ${ }^{(1)}$; no entanto, não constitui marcador prognóstico ${ }^{(10)}$. Tem sido relatado que os indivíduos com infecção pelo HIV apresentam disfunção das células $C D 8^{(14)}$. A possível associação entre a maturação das células CD8 e o controle imune é sugerida ${ }^{(14)}$. No entanto, mais estudos são necessários para avaliar o quanto a maturidade das células CD8 está ligada ao controle da replicação viral ${ }^{(14)}$. Estudo recente $^{(4)}$ sugere que a atividade das células CD8 não controla adequadamente a replicação viral e parece ser criticamente dependente das células CD4 ${ }^{(16)}$. No presente estudo, não houve diferença na contagem média de células CD8 nos grupos avaliados. Como este parâmetro não tem sido utilizado em outros estudos que avaliam esta população de pacientes, fica difícil estabelecer comparação com outras casuísticas. 
Normalmente, na ausência de infecção pelo HIV, a relação entre a contagem de células CD4 e CD8 (CD4/CD8) é maior ou igual a 1. Essa relação é invertida na presença da infecção pelo HIV e assim se mantém por toda a evolução da doença, sintomática ou assintomática; raramente volta a ser maior que 1 novamente ${ }^{(17)}$. Nesta série, a proporção de pacientes com relação CD4/CD8 menor que 1 foi semelhante nos dois grupos avaliados.

No que tange à viremia, estudo italiano ${ }^{(3)}$ avaliou a interação entre o VHC e o HIV, relatando que a baixa carga viral do HIV estava associada com a manutenção do status não-progressor da doença promovida pelo HIV a longo prazo em pacientes co-infectados com VHC.

A maioria dos pacientes co-infectados incluídos para tratamento anti-VHC, apresenta CV-HIV indetectável, com percentual variando entre $60 \%$ e $81 \%$ dos $\operatorname{casos}^{(6,20,32)}$.

$\mathrm{Na}$ presente casuística, a carga viral do HIV média foi de $83.744,2$ cópias/mL no grupo 1 , não havendo diferença significativa em relação à média observada no grupo $2(104.464,0)$; a carga viral do HIV foi indetectável em $70(44,3 \%)$ pacientes do grupo 1 e em $37(29,6 \%)$ do grupo $2(P=0,011)$. Deve ser destacado que $38,9 \%$ dos pacientes do grupo 1 e $60,1 \%$ do grupo 2 não se encontravam em uso de ARV no momento da inclusão no estudo, o que poderia justificar a carga viral do HIV elevada.

Em relação ao uso de ARV, a maioria dos pacientes coinfectados $(91,7 \%)$ e dos monoinfectados pelo HIV $(89,9 \%)$ estava em uso de HAART ou apresentava estado imunológico relativamente preservado que prescindia do uso de $\mathrm{ARV}$, conforme refletido na contagem de células $\mathrm{CD} 4$, não tendo havido diferença estatisticamente significativa entre o tratamento ARV instituído aos dois grupos de pacientes avaliados.

Do presente estudo, conclui-se que os pacientes co-infectados e os monoinfectados por HIV apresentaram características de imunidade semelhantes.

Tovo CV, Santos DE, Mattos AZ, Mattos AA, Santos BR, Galperim B. Evaluation of the cellular immunity in patients coinfected by the hepatitis C virus and the human immunodeficiency virus. Arq Gastroenterol. 2007;44(2):113-7.

ABSTRACT - Background - The immune activation provoked by the hepatitis C virus can be deleterious in patients with human immunodeficiency virus, favouring the destruction of CD4 cells. By the other side, the immune restoration observed after the onset of antiretroviral therapy can be partially obscured in patients with the hepatitis C virus. Aim - The objective of the present study was to evaluate the impact of coinfection by hepatitis $\mathrm{C}$ virus and the human immunodeficiency virus in the cellular immunity. Methods - Two groups of patients were considered: coinfected patients were prospectively evaluated in the gastroenterology clinic at "Hospital Nossa Senhora da Conceição", Porto Alegre, RS, Brazil (group 1 - 385 patients), and monoinfected patients by human immunodeficiency virus based on the review of the charts from the infectious diseases clinic (group $2-198$ patients). Demographic (gender, race, age) CD4 and CD8 cell count, CD4/CD8 index and human immunodeficiency virus viral load were evaluated. A 5\% significance level was adopted. Results - There were no difference between the parameters evaluated: mean CD4 count (374,7 $\pm 215,7 \times 357,5 \pm 266,0), \mathrm{CD} 8(1.512,4 \pm 7.274,6 \times 986,7 \pm 436,4)$ and HIV viral load $(83.744,2 \pm 190.292,0 \times 104.464,0 \pm 486.880,5)$ respectively in both groups evaluated, as well as the proportion of patients with CD4/CD8 rate below 1. Conclusion - Coinfection by both viruses did not have a negative impact in relation to monoinfection by human immunodeficiency virus, and the immune profile was similar in all groups.

HEADINGS - Immunity, cellular. Hepacivirus. HIV. 


\section{REFERÊNCIAS}

1. Alatrakchi N, Graham CS, He Q, Serman KE, Koziel MJ. CD8 cell responses to hepatitis $\mathrm{C}$ virus in the liver of persons with HCV-HIV coinfection versus HCV monoinfection. J Infect Dis. 2005;191:702-9.

2. Alter MJ. Epidemiology of hepatitis C in the west. Semin Liver Dis. 1995;15:5-14.

3. Bagaglio S, Ghezzi S, Lodrini S, Vicenzi E, Santagostino E, Carminati G. Hepatitis $\mathrm{C}$ virus infection in HIV-infected long term non progressors [abstract]. J Hepatol. 2003;38 Suppl 2:125

4. Benito JM, López M, Soriano V. The role of $\mathrm{CD} 8^{+} \mathrm{T}$-cell response in HIV infection. AIDS Rev. 2004;6(2):79-88.

5. Chung RT, Andersen J, Volberding P, Robbins GK, Liu T, Sherman KE, Peters MG, Koziel MJ, Bhan AK, Alston B, Colquhoun D, Nevin T, Harb G, van der Horst C, AIDS Clinical Trials Group A5071 Study Team. Peginterferon alfa-2a plus ribavirin versus interferon alfa-2a plus ribavirin for chronic hepatitis $\mathrm{C}$ in HIV co-infected persons. N Engl J Med. 2004;351:451-9.

6. Di Bisceglie AM. Hepatitis C. Lancet. 1998;351:351-5.

7. Di Martino V, Rufat P, Boyer N, Renard P, Degos F, Martinot-Peignoux M, Matheron S, Le Moing V, Vachon F, Degott C, Valla D, Marcellin P. The influence of human immunodeficiency virus co-infection on chronic hepatitis $\mathrm{C}$ in injection drug users: a long-term retrospective cohort study. Hepatology. 2001;34:1193-9.

8. Dieterich DT. Hepatitis $\mathrm{C}$ virus and human immunodeficiency virus: clinical issues in co-infection. Am J Med. 1999;107:79s-84s.

9. Dorucci M, Pezzotti P, Phillips NA, Lepri AC, Rezza G (for the Italian Seroconversion Study). Co-infection of hepatitis $\mathrm{C}$ virus with immunodeficiency virus and progression to AIDS. J Infect Dis. 1995; 172:1503-8.

10. Fahey JL, Taylor JM, Detels R, Hofmann B, Melmed R, Nishanian P, Giorgi JV. The prognostic value of cellular and serologic markers in infection with human immunodeficiency virus type 1. N Engl J Med. 1990;322:166-72.

11. Graham CS, Curry M, He Q, Afdhal N, Nunes D, Fleming C, Horsburgh R, Craven D, Sherman KE, Koziel MJ. Comparison of HCV-specific intrahepatic CD4+ T cells in HIV/HCV versus HCV. Hepatology. 2004;40:125-32.

12. Greub G, Ledengerber B, Battegay M, Grob P, Perrin L, Furrer H, Burgisser P, Erb P, Boggian K, Piffaretti JC, Hirschel B, Janin P, Francioli P, Flepp M, Telenti A. Clinical progression, survival, and immune recovery during antiretroviral therapy in patients with HIV-1 and hepatitis C virus co-infection: the Swiss HIV Cohort Study. Lancet. 2000;356:1800-5.

13. Halfon P, Ouzan D, Cattan L, Cacoub P. The diagnostic tools of hepatitis C virus infections. Presse Med. 2004;33:538-41.

14. Hess C, Altfeld M, Thomas SY, Addo MM, Rosenber ES, Allen TM, Draenert R, Eldrige RL, van Lunzen J, Stellbrink HJ, Walker BD, Luster AD. HIV-1 specific CD8+ T cells with an effector phenotype and control of viral replication. Lancet. 2004;363:863-6.

15. Jackson JB, Parsons JS, Nichols LS, Knoble N, Kennedy S, Piwowar EM. Detection of human immunodeficiency virus type 1 (HIV-1) antibody by western blotting and HIV-1 DNA by PCR in patients with AIDS. J Clin Microbiol. 1997;35:1118-21.

16. Kim AY, Lauer GM, Ouchi K, Addo MM, Lucas M, Schulze Zur Wiesch J, Timm J, Boczanowski M, Duncan JE, Wurcel AG, Casson D, Chung RT, Draenert R, Klenerman $\mathrm{P}$, Walker BD. The magnitude and breadth of hepatitis $\mathrm{C}$ virus-specific CD8+ T cells depend on absolute CD4+ T-cell count in individuals coinfected with HIV-1. Blood 2005;105:1170-8.

17. Laurence J. T-cell subsets in health, infectious disease, and idiopathic CD4 T lymphocytopenia. Ann Intern Med. 1993;119:55-62.

18. Lessens O, Deschenes M, Steben M, Belanger G, Tsoukas CM. Hepatitis C virus is related to progressive liver disease in human immunodeficiency virus-positive hemophiliacs and should be treated as an opportunistic infection. J Infect Dis. 1999; 179:1254-8.
19. Miller MF, Haley C, Koziel MJ, Rowley CR. Impact of hepatitis C virus on immune restoration in HIV infected patients who start highly active antiretroviral therapy: a meta-analysis. Clin Infect Dis. 2005;41:713-20.

20. Myers RP, Benhamou Y, Boche M, Thibault V, Mehri D, Poynard T. Pegylated interferon alpha $2 \mathrm{~b}$ and ribavirin in HIV/hepatitis $\mathrm{C}$ virus co-infected non-responders and relapsers to IFN-based therapy. AIDS. 2004;18:75-9.

21. Piroth L, Duong M, Quantin C, Abrahamowicz M, Michardiere R, Aho LS, Grappin M, Buisson M, Waldner A, Portier H, Chavanet P. Does hepatitis C virus co-infection accelerate clinical and immunological evolution of HIV-infected patients? AIDS 1998; $12: 381-8$

22. Rockstroh JK, Mocroft A, Soriano V, Tural C, Losso MH, Horban A, Kirk O, Phillips A, Ledergerber B, Lundgren J, EuroSIDA Study Group. Influence of hepatitis C virus infection on HIV-1 disease progression and response to highly active antiretroviral therapy. Infect Dis 2005; 192:992-1002.

23. Rosen HR, Miner C, Sasaki AW, Lewinsohn DM, Conrad AJ, Bakke A, Bouwer HG, Hinrichs DJ. Frequencies of HCV-specific effector CD4+ T cells by flow cytometry: correlation with clinical disease stages. Hepatology. 2002;35:190-8.

24. Sabin CA, Telfer P, Phillips NA, Bhagani S, Lee CA. The association between hepatitis $\mathrm{C}$ virus genotype and human immunodeficiency virus disease progression in a cohort of hemophilic men. J Infect Dis. 1997;175:164-8.

25. Shaw GM. Biology of human immunodeficiency viruses. In: Goldman L, Ausiello D, editors. Cecil textbook of medicine. 22nd ed. Philadelphia: Saunders; 2004 p. $2139-44$.

26. Soriano V, Garcia-Samaniego J, Rodriguez-Rosado R, Gonzalez J, Pedreira J. Hepatitis $\mathrm{C}$ and HIV infection: biological, clinical, and therapeutic implications. J Hepatol 1999;31 Suppl 1:119-23.

27. Soriano V, Rodriguez-Rosado R, Garcia-Samaniego J. Management of chronic hepatitis C in HIV-infected patients. AIDS. 1999;13:539-46.

28. Soriano V, Puoti M, Sulkowski M, Mauss S, Cacoub P, Cargnel A, Dieterich D, Hatzakis A, Rockstroh J. Care of patients with hepatitis C and HIV co-infection. AIDS. 2004;18:1-12.

29. Staples CT, Rimland D, Dudas D. Hepatitis C in the HIV Atlanta VA Cohort Study (HAVACS): the effect of co-infection on survival. Clin Infect Dis. 1999;29:150-4.

30. Sulkowski MS, Mast EE, Seeff LB, Thomas DL. Hepatitis C virus infection as an opportunistic disease in persons infected with human immunodeficiency virus. Clin Infect Dis. 2000;30:s77-s84.

31. Sulkowski MS, Moore RD, Mehta SH, Chaisson RE, Thomas DL. Hepatitis C and progression of HIV disease. JAMA. 2002;288:199-206.

32. Torriani FJ, Rodriguez-Torres M, Rockstroh JK, Lissen E, Gonzalez J, Lazzarin A, Carosi G, Sasadeusz J, Katlama C, Montaner J, Sette H, Passe S, De Pamphilis J, Duff F, Schrenk UM, Dieterich DT, APRICOT Study Group. Peginterferon alfa-2a plus ribavirin for chronic hepatitis $\mathrm{C}$ virus infection in HIV-infected patients. $\mathrm{N}$ Engl J Med. 2004;351:438-50.

33. World Health Organization. Hepatitis C global prevalence (update). Wkly Epidemiol Rec. 2000;75:17-28.

34. Wright TL, Hollander H, Pu X, Held MJ, Lipson P, Quan S, Polito A, Thaler MM, Bacchetti P, Scharschmidt BF. Hepatitis C in HIV-infected patients with and without AIDS: prevalence and relationship to patient survival. Hepatology. 1994;20:1152-5. 